\section{artelogie}

\section{Artelogie}

Recherche sur les arts, le patrimoine et la littérature de l'Amérique latine

$12 \mid 2018$

Idiosyncrasie de l'indigénisme en Amérique latine.

Pluralité des sources et des appropriations extra-

latino-américaines

\title{
Continuidades de algunos movimientos artísticos rioplatenses : Anna Rank, Marcelo Larrosa y Judith Brítez
}

\section{Ma. Eugenia Méndez-Marconi}

\section{QpenEdition \\ Journals}

Edición electrónica

URL: http://journals.openedition.org/artelogie/2439

DOI: 10.4000/artelogie.2439

ISSN: 2115-6395

Editor

Association ESCAL

Referencia electrónica

Ma. Eugenia Méndez-Marconi, « Continuidades de algunos movimientos artísticos rioplatenses : Anna

Rank, Marcelo Larrosa y Judith Brítez », Artelogie [En línea], 12 | 2018, Publicado el 07 septiembre 2018, consultado el 10 diciembre 2020. URL : http://journals.openedition.org/artelogie/2439 ; DOI : https://doi.org/10.4000/artelogie.2439

Este documento fue generado automáticamente el 10 diciembre 2020.

Association ESCAL 


\title{
Continuidades de algunos
} movimientos artísticos rioplatenses : Anna Rank, Marcelo Larrosa y Judith Brítez

\author{
Ma. Eugenia Méndez-Marconi
}

1 En el siglo XX, se suscitaron fervientemente diversos cambios en el arte, que generaron nuevos paradigmas conceptuales y expresiones estéticas.

2 En el Río de la Plata, surge a partir del retorno del Maestro Joaquín Torres-García a Montevideo en 1934, una nueva manifestación del arte, expuesta y fundamentada por él, a partir de sus múltiples conferencias y publicaciones. En consecuencia, formó el ya mítico Taller Torres-García (TTG), posteriormente denominado Escuela del Sur. En dicho Taller se formaron destacados artistas de gran calidad plástica, entre los cuales podemos nombrar a Augusto y Horacio Torres (ambos hijos del Maestro), Julio Alpuy, Francisco Matto, Anhelo Hernández, Elsa Andrada, entre otros.

3 El Maestro Torres-García propone una visión de la Gran Tradición Universal, que se manifiesta también como una Tradición Universal en el Arte, con expresiones en tradiciones históricas locales.

4 Esa Visión Universalista le permite a Torres-García fundamentar una propuesta para arraigar en las tradiciones indoamericanas, partiendo de referentes del Horizonte Mediterráneo en el cual él se desarrolló inicialmente; y esto es logrado al profundizar en los elementos universales comunes -tanto de tradiciones indoamericanas como de tradiciones mediterráneas-, y en contemplar las diferencias irreductibles entre ellas; evitando la apropiación cultural, y otros tipos de plagio y descontextualización.

5 Asimismo, su visión holística, proponía un arte basado en las mismas leyes que rigen la configuración del universo; como ser la Sección Áurea y la geometría, ya descubiertas y utilizadas por antiguas civilizaciones. 
6 La obra por lo tanto, desde esta visión, se contempla como una unidad evidenciada por la armonía manifiesta mediante la estructura y el tono, en correspondencia con la totalidad de los elementos compositivos absolutos.

Luego de la influencia Torresgarciana, desde la vecina orilla en Buenos Aires, comienzan a plantearse nuevas alternativas en el arte. Y a partir de 1946 surge el Movimiento Madí, conformado por los uruguayos Carmelo Arden Quin y Rhod Rothfuss, y por Gyula Kosice (checoslovaco nacionalizado como argentino); quienes ya se habían agrupado junto a Tomás Maldonado y otros artistas y literatos, para la publicación de la revista Arturo en 1944 -para la cual colaboraron también Joaquín Torres García, Piet Mondrian, y Wassily Kandinsky-.

8 El Movimiento Madí, lleva al arte -en todas sus manifestaciones- a una abstracción extrema, que busca partir puramente desde la invención, con el fin de liberar la creación del artista de cualquier reminiscencia externa, para articular formas en sí mismas.

9 Los artistas plásticos Anna Rank, Marcelo Larrosa y Judith Brítez, trabajan siguiendo estas estéticas rioplatenses con fuerte base en la geometría: El Constructivismo Torresgarciano y el Arte Madí.

10 Anna Rank y Marcelo Larrosa, provienen de la Tradición Constructivista Torresgarciana; y Judith Brítez trabaja siguiendo los lineamientos Madí.

11 Anna Rank, nacida en Montevideo y actual residente en Buenos Aires, comenzó sus estudios en dibujo y pintura a partir de 1977 hasta 1978 con Hilda Varela -su madre, quien a su vez se formó en el TTG con los maestros José Gurvich y Julio Alpuy-. Continúo su formación con Antonio Pezzino y postreramente en 1983 con Julio Alpuy, con quien retomaría en 1986 a 1988. Es Magister de Bellas Artes por Parsons, The New School for Design, New York. Y actualmente dicta clases en su taller particular, además de ser convocada para dictar diversos seminarios y cursos en distintas instituciones.

12 Sus obras con bases en concepciones de la Tradición Torresgarciana, incorporan la idea de deconstrucción presente en el Post-humanismo. Sus dibujos, relieves y formas en alambre, están realizadas en una búsqueda de un arte sintético que tiene por base la geometría y la abstracción. Sus formas que remiten a la figura humana, presentan estructuras orgánicas llevadas a la simplicidad del signo en una síntesis mayor.

13 Marcelo Larrosa, nacido en Montevideo, estudia escultura con el artista Carlos Medina en Venezuela en 1997. Posteriormente forma parte del grupo La Piedra, junto a otros artistas. Conoce y frecuenta en 1998 al maestro Julio Alpuy en Montevideo, e ingresa al taller del maestro Anhelo Hernández en el Instituto Escuela Nacional de Bellas Artes de Uruguay (IENBA) de la Universidad de la República (UDELAR). Continúa sus estudios con el maestro Julio Alpuy entre los años 2003 y 2005, en su estudio particular en New York. Actualmente es Docente de Dibujo y Pintura en el IENBA-UDELAR.

14 Sus obras en pintura presentan estructuras conformadas a partir de letras, inspiradas en los signos expresivos de las notaciones cuadradas de los cantos gregorianos -en relación a cómo se configuran los ritmos de las letras-; en una reconfiguración de las estructuras ortodoxas Torresgarcianas. Sus esculturas en hierro, trabajadas con diferentes pátinas y óxidos, son formas que presentan ciertas características sígnicas, donde predominan las líneas rectas y curvas, con fuerte geometría y abstracción.

15 Judith Brítez, nace en Montevideo, y realiza sus primeras experiencias plásticas en el taller de sus abuelos maternos, Maddalena Mori y Vicenzo Di Sano. Continúa sus estudios 
en 1996 en la Universidad del Trabajo (UTU) y en 1997 en el IENBA-UDELAR. En 2002 obtiene una beca para estudiar en Florencia, Italia; y en el mismo año estudia con el escultor Federico Arnaud. Es Licenciada en Psicología desde el 2008. En 2009 conoce a la Sra. Sofía Kunst de Arden Quin, quien la conecta con el Movimiento Madí Argentino. A la fecha continúa investigando en el Arte Textil, en la Escuela Pedro Figari (UTU). Sus obras en hierro conforman formas simples, que dialogan entre huecos y calados geométricos, en un estilo abstracto ligado a la estética Madí. Sus últimos trabajos textiles, se encuentran en concordancia con los hierros, mediante una correspondencia entre la simplicidad de las formas representadas; adquiriendo la riqueza del entramado rústico de los materiales trabajados.

Estos tres artistas se presentan en conjunto, revalorizando y reconfigurando tradiciones que les preceden, dando nuevas expresiones del arte actual Constructivista y Madí; unidos en la aspiración de integrarse en la Gran Tradición Universal del Arte.

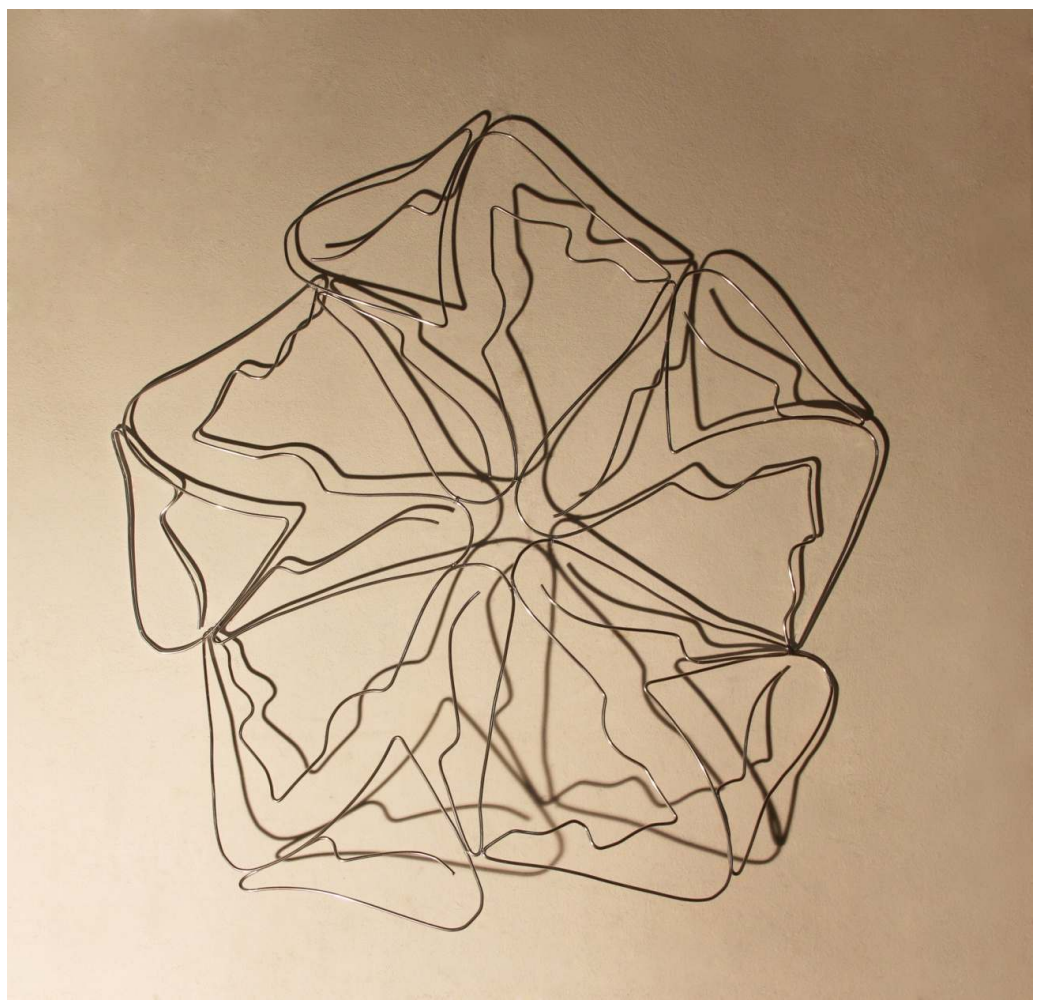

Anna Rank

Caleidoscopio humano (Human kaleidoscope).

$117 \times 117 \times 05 \mathrm{~cm}$

Alambre de aluminio

2017 


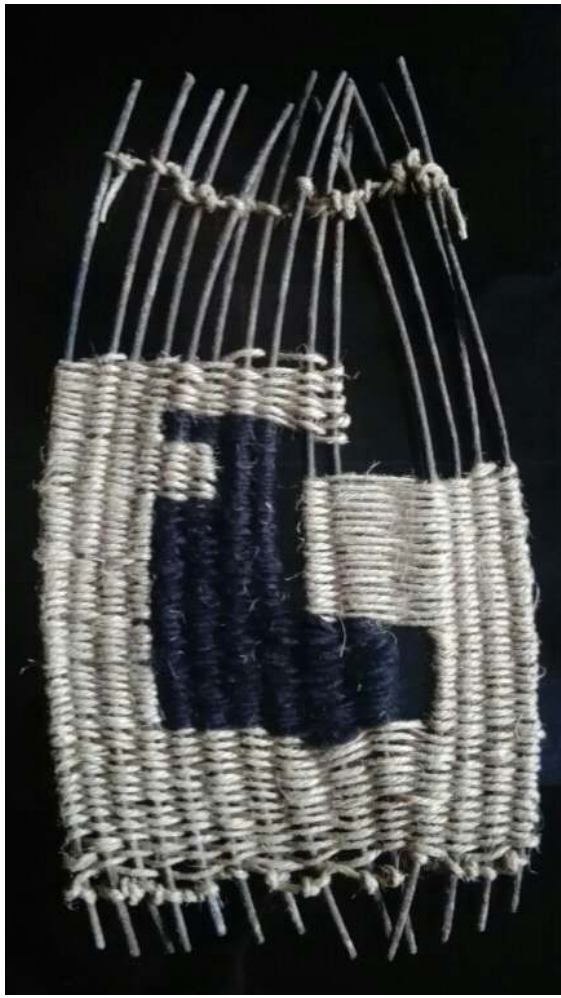

Judith Estela Brítez Di Sano, 27cm x 14,5cm, Textil, 2018

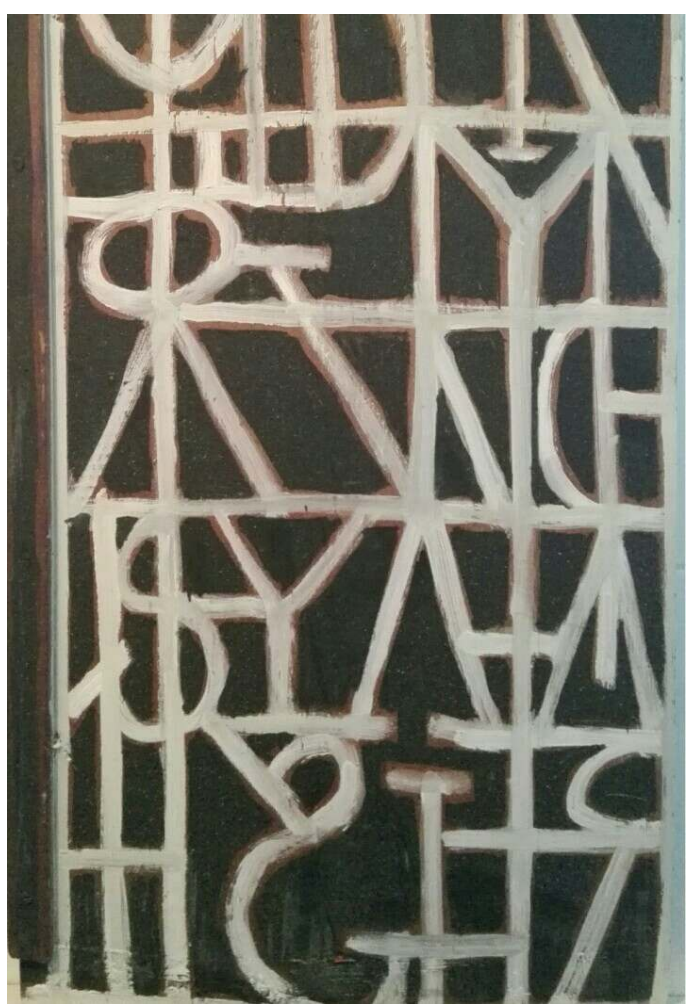

Marcelo Larrosa Martinatto

Construcción en negro

$66 \mathrm{~cm} \times 39 \mathrm{~cm}$

Óleo sobre tabla

2016 


\section{RESÚMENES}

En el siglo XX, se suscitaron fervientemente diversos cambios en el arte, que generaron nuevos paradigmas conceptuales y expresiones estéticas. En el Río de la Plata, surge a partir del retorno del Maestro Joaquín Torres-García a Montevideo en 1934, una nueva manifestación del arte, expuesta y fundamentada por él, a partir de sus múltiples conferencias y publicaciones. En consecuencia, formó el ya mítico Taller Torres-García (TTG), posteriormente denominado Escuela del Sur. En dicho Taller se formaron destacados artistas de gran calidad plástica, entre los cuales podemos nombrar a Augusto y Horacio Torres (ambos hijos del Maestro), Julio Alpuy, Francisco Matto, Anhelo Hernández, Elsa Andrada, entre otros.

\section{AUTOR}

\section{MA. EUGENIA MÉNDEZ-MARCONI}

Ma. Eugenia Méndez-Marconi, Museóloga (Universidad de la República), Docente G1 Instituto Escuela Nacional de Bellas Artes (Universidad de la República), Docente Comunicación Visual y Artes Plásticas (Educación Secundaria), Exposiciones e investigación en la Fundación José Gurvich - Museo Gurvich, Artista plástica. 